\title{
Different by Culture
}

\section{Toward an Analysis of Age(ing) in Care Homes for Older People}

\author{
Marie-Kristin Doebler® \\ Institute of Sociology, University of Tübingen, Germany and Institute of Sociology, Friedrich-Alexander University \\ Erlangen-Nuremberg, Germany
}

\begin{abstract}
This article suggests that the term "culture" can explain the heterogeneity of age(ing) in nursing homes as well as (dis-)similarities opposed to organizational parameters (e.g., size, location, ownership). It introduces an analytical tool for the systematic analysis of culture which encompasses 15 thematic dimensions grouping as conceptualizations of age(ing), social relationships, and care. Two nursing homes from an explorative project in Bavarian nursing homes are used for illustrating the tool's possible applications: systematic description, explanation, and comparisons of locally effective cultures; determining ambivalences' manifestations and sources. The article ends with a discussion of underlying implications of the findings for theory and praxis and the benefits and weaknesses of this study, connected with the hope to broaden the perception of nursing homes which are more than organizations designed to house older people safely; they are also culturally shaped places of social life.
\end{abstract}

Keywords: age(ing), care, intergenerational relations/family, solidarity, culture

Against the backdrop of the explorative project "Quality of Life in Bavarian Nursing Homes for Older People," this paper claims that more than organizational parameters must be considered to account for late-life in nursing homes. Rather, culture governs relevant thinking, (inter-) acting, and living. The adopted concept of culture refers neither to a particular national nor ethnical differentiations nor to what is discussed as "organizational culture," where culture is primarily considered at the level of employees (McDaniel \& Stumpf, 1993; Scott-Findlay \& Estabrooks, 2006). Instead, drawing on practice and pragmatic theories, culture is seen as "performative," indicating that all home-internal (inter-)actions are relevant. Furthermore, culture is "insubstantially" interpreted as the cause and effect of different but regularly appearing ways of living, thinking, and (inter-)acting (Hall \& Neitz, 1993; Jenks, 1993). These are supposed to offer particular solutions to ontological, epistemological, and teleological problems common to all humans and issues central to life (Artner, 2018; Hills, 2002; Tam, 2014; Vries, 2018) and to reveal themselves in people's doings and sayings (Lehmann \& Brinkmann, 2019). This conceptualization makes culture a system of signs and symbols as well as a mode or medium of comparisons (Jenks, 1993). Therefore, this article stipulates neither the existence of cultures nor the presence of cultural differences but rather acknowledges that any social unit can be a possible reference point. It presumes that underlying sets of ideas, values, norms, rules, interpretations, and types of structuring interactions and social life
(Michel \& Peng, 2017; Peng, 2018; Schultz Lee, 2010) vary systematically, and that this can be used for identifying interhome and intrahome (dis)similarities on various levels such as individuals (micro), collectives/teams (meso), or the macrolevel of corporate culture, home management, ownership and legal form, family regimes or societies (Jenks, 1993; Esping-Andersen, 1999; McDaniel \& Stumpf, 1993).

Against this backdrop, the article's objectives are as follows:

- To elaborate the presumption that referring to locally effective cultures describes life and experiences in nursing homes more precisely than referring to organizational parameters (alone).

- To introduce an analytical tool designed (a) to register facets of life in old people's homes neglected when solely looking at "organizational parameters"; (b) to identify (dis-)similarities lying cross to organizations but are attributable to cultures; (c) to grasp and compare effective cultures in a nuanced, systematic way; (d) to describe and explain the manifestation of ambivalences (Bengtson et al., 2002; Connidis \& McMullin, 2002; Lüscher \& Hoff, 2013).

The following sections sketch the theoretical background of the aforementioned project and depict the development of the analytical tool. I then describe the methods and the sample of the qualitative study from which the two cases 
are drawn used for illustrative purposes. Thereafter, I discuss the overall findings concerning "ambivalences" as an example of transversal themes as well as with an eye toward the project's limitations. By pointing out the implication for future research, theory, and practice, I conclude that highlighting the importance of culture, and offering a tool to capture and describe it systematically, makes an important contribution to the body of research about age(ing), especially in inpatient settings, in hopes of broadening the perception of old age in nursing homes, namely, that they are culturally shaped places of social life.

\section{Study Background}

The "Quality of Life in Bavarian Nursing Homes for Older People" project started by analyzing existing research and theories about quality of life in old age (Clark \& Bowling, 1990; Daatland, 2016; Farquhar, 1995; Staehlin, 2016) and especially in nursing homes (Clark \& Bowling, 1990; Lang et al., 2007; Mattiasson \& Andersson, 1997; Veer \& Kerska, 2001; Westin \& Danielson, 2007). In so-called modern Western societies, (long-term) care facilities are increasingly becoming commonplaces of living for people typically at least 65 years old with a (growing) need for support (Barnes, 2006; Federal Statistical Office, 2016). The assistance provided by nursing-home employees is designed to cover a broad range of needs, including housekeeping, personal hygiene, or help with eating/drinking. Additionally, nursing homes usually offer various kinds of therapy and occupational opportunities.

Despite sharing these characteristics, life within such homes is extremely diverse. Existing literature on old-age inpatient care refers to organizational differences to explain this empirically observable heterogeneity (Artner, 2018; Barnes, 2006; Döbler, 2019b; Federal Statistical Office, 2016; Kane, 2001; McDaniel \& Stumpf, 1993). This presumption is common but not limited to research drawing on Goffman's (1961) work on inpatient housing and care elaborated in "asylums" (Heinzelmann, 2004; Kelle et al., 2014). Respective studies investigate, for instance, whether and how much nursing homes resemble the "ideal type" of a total institution (Goffman, 1961) or what needs or can be done on the organizational level to create less totalistic conditions thought to adversely affect residents (Shadish \& Bootzin, 1984; Zweig \& Oliver, 2009). Consequently, several studies about institutionalized life in old age share a rather one-sided perspective of nursing homes based primarily on numbers (size of home, number of beds, number of employees), location, and ownership, which are thought to account for differences. However, considering only (or at least primarily) these organizational parameters tends to neglect many facets of age(ing) and leaves existing differ- ences unexplained: Nursing homes are also places of living, loving, laughing, etc., characterized by their population (inhabitants and staff) and how they work together, how they (can) shape their daily routine, how they perceive their (fellow) residents, how they care for others or for each other, etc. This became apparent already in an early phase of the empirical investigation, based on the first field visits, which triggered a change in the direction of this project. Rather than limiting the analysis to the organizational aspects, Goffman's (1961) elaborations about interactions were increasingly acknowledged: In addition to the organizational characteristics of total institutions (all-encompassing; life within a single place under central authority; precise planning of days and all activities; prescribed sequences and explicit rules subjected to institutions' official rational plan and goals), Goffman deals with the impact of practices and the role of "microbehavior." For him, (inter-)actions shape the daily life of the "inmates" (Goffman, 1961, pp. 125-170) just as much as the institutions' general, formal, and material structure. He observed an "underlife" that potentially subverts the organization (Goffman, 1961, pp. 171-320). Thus, already Goffman pointed out that thinking solely in organizational terms fails to account for the whole picture, and that other concepts are needed to adequately cover observable age(ing) on site. This article proposes that culture, as defined previously, presents as an alternative and thus an analytical tool for its analysis.

\section{An Analytical Tool for Analyzing the Locally Effective Culture of Care Homes}

Informed by thematic analysis (Braun \& Clarke, 2006), I explored the research landscape qualitatively by first gaining an overview of the publications dealing with ag (ing) and care in general, and age(ing) within inpatient care facilities in particular. I based this on a keyword search (aging, care, and various names for inpatient care facilities, e.g., nursing home, home for older people) conducted in various databases of journals considered relevant to the study of aging and care, including but not limited to the following: Journal of Aging Studies, Journal of the American Society on Aging, Journal of Advanced Nursing, Journal of Cross-Cultural Gerontology, Journal of Housing for the Elderly. Then, I qualitatively skimmed the abstracts, keywords, and articles regarded as most relevant to the field of interest, subjecting them to a more detailed, even close reading process during which I identified reoccurring themes. The final result was a list of 15 topics (cf. Figure 1) that specify the rather abstract, general idea related to culture that ontological, social, and teleological issues matter in the context of age(ing) in nursing homes, as well as to 


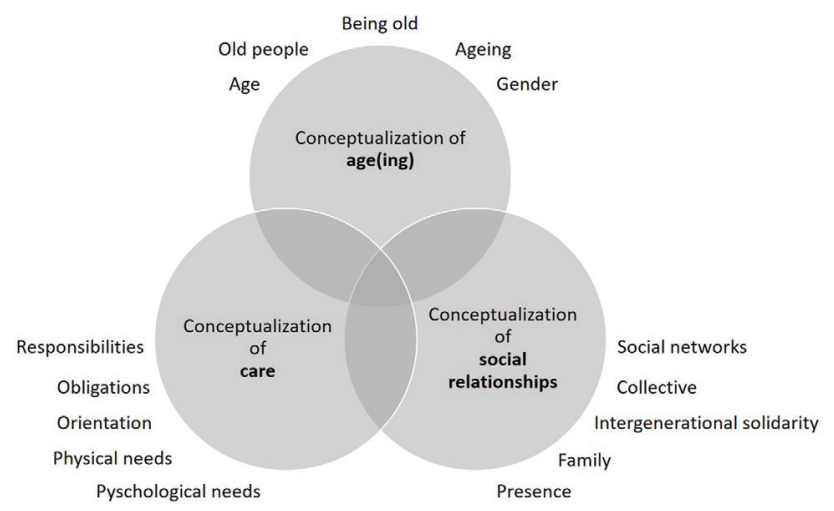

Figure 1. Dimensions and conceptualization relevant for analyzing differences of age(ing).

the group as conceptualizations of (old-)age, social relationships, and care (cf. Figure). Further, I conceptualized these 15 topics as thematic continua spanning the two poles representing opposing attitudes on the respective topic. First, conceiving themes as dimensions reflects that they are not only discussed excessively in the literature, but that this is done concerning contrasts. Second, it acknowledges complexities: Perspectives may tend toward a pole, although they are often more precisely positioned between the extremes.

I then consolidated these insights, resulting in the draft of an analytical instrument that is supposed to aid in (a) the nuanced description of age(care) constellations; (b) the identification, differentiation, and comparison of cultures; and (c) the explanation of related consequences for those living and working within care homes. Because of its intended abstract character, this analytical tool is rarely found in pure form in empirical reality; instead, it serves to help order things, just like the Weberian ideal types and the Goffmanian idea of a "total institution" do.

\section{Conceptualizations of Age(ing)}

Conceptualizations of age(ing) and related conditions or temporal changes revolve primarily, though not exclusively, around ontological considerations in trying to figure out the nature of

- what is conceived as (old-)age,

- the processes of aging and the passing through different statuses or phases of life,

- being old, an old person, or of old people in general,

- the relation to other, seemingly unchangeable human traits such as gender.

Age may either be seen either as a category or as a phase of life. While the former demarcates life associated with youth from decay and dysfunctionality associated with (old) age (Van Dyk, 2014, 2016), the latter connects to an idea of anthropological similarity with related guidelines for thinking and behaving. Especially demarcations tend to co-appear with age-unequal treatment possibly freeing from expectations and pressures directed at younger people or resulting in discrimination (cf. the contributions in Ayalon \& Tesch-Roemer, 2018). However, an emphasis on anthropological similarity may also cause inequality, for instance, if particular vulnerabilities and needs are neglected or social differences, effective in old age and heterogeneities of "the old," are ignored (Degnen, 2007; Rupprecht et al., 2019).

Just like age-related conditions, the temporal processes of aging can be perceived as heterogeneous (Gubrium, 2016; Pickard, 2019) or homogeneous. While conceiving aging as unavoidable change or natural course of human life may free from responsibilities, acknowledging the contingency of aging raises questions about individual responsibilities and societal accountabilities concerning advance planning, reasonable lifestyles, healthy and prudent living (Cardona, 2008; Park et al., 2019; Pfaller \& Schweda, 2019; Romaioli \& Contarello, 2019). Further, appreciating the mutability of aging can come with an awareness of the impact of social differences or contextual factors on aging (resources, infrastructures, etc.) ignored by those taking the former position (Degnen, 2007; Park et al., 2019; Romaioli \& Contarello, 2019). Additionally, regarding aging (until) death as a process of becoming may require life-long learning, activity, or productivity, etc., whereas equating aging with processes of loss and decay can cause or legitimize exclusions from social spaces. The resulting spatial separations of young and old are ambiguous as the creation of age-specialized spaces can either be tailored at hiding the "abject age" (Gilleard, 2016; Kristeva, 1982; van Dyk, 2016) or at meeting age-related needs. Likewise, decategorizations and recategorizations linked with becoming or being old may free one from stereotypical demands and be characterized by certain entitlements, such as the ability to retire and relax (Foster \& Walker, 2015; Tam, 2014). While this can be beneficial, for instance, for those old people who do not want or no longer meet the requirements of having a productive, active life (Pfaller $\&$ Schweda, 2019; van Dyk, 2016), others may lose their sense of life if confined to idleness.

Decategorizations and recategorizations may have further detrimental effects, for instance, in the context of gender: $\mathrm{Be}(\mathrm{com})$ ing old seems to challenge the reproduction of gender identities (Dittmann-Kohli, 2016; Gilleard, 2016). It seems that aging prevents one from being female/ male (Allen \& Cherry, 2006; Biggs, 2004; Einiö, Guilbault, Martikainen, \& Poulain, 2012) or that aging results in processes of feminization. This is based on several processes, such as the exclusion from the nondomestic area 
of productivity and the confinement to the private realm associated with masculinity and femininity, respectively, or the fact that the population in nursing homes (both staff and inhabitants) are predominantly women, where the recreational or leisure activities offered are (at least perceived as) primarily female.

\section{Conceptualizations of Social Relationships}

Besides structural features such as mobility, spatial distance, etc. (Craveiro et al., 2013), social life is impacted by conceptualizations of social relationships regarding

- size, foundation, density, reliability, and functionality of social networks (Crossley et al., 2015; Lüscher, 2002),

- forms and degrees of presence, i.e., who should be present for whom in which way, intensity, and frequency (Döbler, 2019a, 2020b),

- consequences of belonging to collectives or families, given and desired nature of interpersonal, intergenerational connectedness and inclusion (Craveiro et al., 2013; Westin \& Danielson, 2007), based either on the quality of relationships (Craveiro et al., 2013; Silverstein, Gans, Lowenstein, Giarrusso, \& Bengtson, 2010; Zhang \& Wang, 2010) or on biological (e.g., blood), legal (e.g., marriage or adoption), or contractual (e.g., with caring staff) groundings.

Taken together, this shapes encounters, integration, and solidarity as well as attitudes and positions regarding considerations like these:

- Are encounters anonymous and superficial or intense and stable, leading, for example, to experiences of isolation, autonomy, and freedom or to ontological security thanks to knowing where one belongs (Giddens, 2003), albeit at the price of a lack of privacy?

- Are older people integrated partially or holistically, that is, are they, for example, reduced to a single role such as being the "old person" or a "nursing-home resident"? Or are they conceived as people with various social roles and individual biographies (Döbler, 2020a)?

- Is solidarity dependent on the quality or nature of the relationship, or is it unconditional and entails a mutual exchange commitment and reciprocity (cf. contributions in Bengtson \& Lowenstein, 2003; Lehmann \& Brinkmann, 2019)?

\section{Conceptualizations of Care}

Conceptualizations of care subsume questions about responsibilities, obligations, and entitlements, measures for determining the rightfulness of physical and psychological needs or desires, and how these can or should be met. Teleological considerations related to dealing with the existential matters, vulnerabilities, trajectories, and boundaries of life frame these just as much as epistemologies do. For instance, responsibility is tied to knowledge associated either with professional training or a shared history. The former comes along with functional differentiations. These tend to co-appear with orientations at efficiency, necessities, often economically defined standards, and professionalization (Cook et al., 2015; Tronto, 2013). While responsibility for physical needs is attributed according to expertise and professional training, psychological matters tend to be dealt with informally. The basis for this is the reference to informal knowledge based on common experiences resulting in a redistribution of responsibilities to the care-receivers' personal network, mainly families (Cook et al., 2015; Döbler, 2019b; Powers, 1992), most often female relatives.

Dividing care responsibilities and assigning competencies to different actors need deny neither their relevance nor the rightfulness of respective desires. Instead, it may imply their availability, provided that required (economic and social) capital and infrastructure exist (Einiö et al., 2012; Pickard, 2019). Certainly, vital necessities - being sated, dressed, dry, and tidy as well as feeling safe - are recognized as relevant and regarded as core duties especially within formally defined settings such as nursing homes. However, there are different interpretations of "vital necessities" and acceptances of supplements to "basic needs" (Cook et al., 2015; Döbler, 2019b; Pickard, 2019). Likewise, which measures (e.g., quality of life, ageappropriateness, economic criteria, or feasibility) are applied to determine the adequacy of care varies (Pickard, 2019; Schweda et al., 2015). Thus, not all conceptualizations of care include the acknowledgment of, let alone respect for, individuality and needs perceived to diverge from what is thought to be standard or absolutely necessary. This is particularly visible regarding psychological or emotional matters related to personal hygiene, food, and occupational offers where investments and evaluation vary with conceptualizations of age(ing) and social relationships.

This indicates what becomes tangible in other respects, too: Dimensions and conceptualizations interrelate in practice. For instance, considerations about intergenerational solidarity are linked to considerations about what being a family, a member of a collective, or being present requires and entails. As each dimension deals with different aspects of social relationships, analyzing them separately allows grasping more facets in more detail and reflecting on the nature and closeness of the association of dimensions. However, their distinction should be understood as an analytical one. 
Additionally, it is tangible that all three conceptualizations relate to ontological, epistemological, and teleological problems that are "answered" by culture. For instance, individuality and self-expertise may be acknowledged especially where ontological considerations emphasize (remaining) capabilities rather than loss (Jecker, 2017; Nussbaum, 2000). In combination with teleological ideas about the interdependencies of life in old and young age that implies self-responsibility and limits intergenerational solidarity (Leopold \& Raab, 2011; Pickard, 2019). While entanglements are evident in practice, the epistemological benefits of analytical separations of dimensions as well as conceptualizations are depicted in the following when applying the analytical tool to two cases studies.

\section{Empirical Study}

The preceding sections depicted the theoretical background of the project and the development of the analytical tool. This section in turn (a) describes the empirical material and (b) illustrates by way of example the analytical tool's use for the analysis of cultures.

\section{Methods and Data}

Qualitative data were gathered in 12 either privately, nonprofitable, or ecclesiastically managed houses. The sampling of homes aimed at covering all governmental districts of Bavaria (Germany) as well as the various organizational characteristics regarding size (30 to 150 beds), location (urban/rural), and ownership (public/private/ religious organizations). In each home, I interviewed the home directors as experts for institutional arrangements and organizational matters as well as asking them to describe the career that had led them to their current professional position. Seven of the interviewed 12 home directors were care-service directors, too. Their age varied between 27 and 62. Additionally, unstructured but documented conversations of varying length (5 to 105 minutes) and intensity (up to 15 questions) were led at least with three staff members in each home; their age ranged between 19 and 63 years. Some of them were still in training, whereas others had been working in eldercare for several decades. Furthermore, (semi)standardized guideline interviews were conducted with a total of 128 residents $(40$ men, 88 women) all aged $65+$ and with diverse officially assigned levels of care (German: Pflegegrad 1-5 or Pflegestufe 1-3).

Since each home had only one home director, the sampling of home directors coincided with the sampling of the homes. The on-site opportunity structures guided the sampling regarding the open conversations with home employees. In the case of residents, the need for basic communicative capacities and the ability to consent to be interviewed represented an exclusion criterion: In accordance with ethical considerations about informed consent and methodological literature about the minimal cognitive requirements for participating in interviews (Hall et al., 2009; Harris \& Dyson, 2001; Maas et al., 2002), I included in the study only residents with a degree of dementia below 4 (Hubbard et al., 2003; Pesonen et al., 2011; Sherratt et al., 2007).

I obtained informed consent at the beginning of each interview. All interviewees were made aware of the chance to interrupt or to end the interview at any time, to withdraw their consent, and that resulting data would be anonymized. While the participation of all respondents was intended to be voluntary, there was a preselection of residents to be interviewed by the employees at the respective home, and it is not entirely transparent to us how this selection was made and how resident interviewees were briefed by them in advance.

I sorted the transcribed and anonymized interviews thematically, selecting passages regarded as rich in information for further heuristic analysis, that is, to be interpreted hermeneutically and openly coded (Braun \& Clarke, 2006). Once the above introduced analytical tool had been developed, the interviews were analyzed accordingly.

\section{Analyzing Differences and Similarities Between Care Homes: Empirically Observable Conceptualizations of Age(ing), Social Relationships, and Care}

What follows sketches the overall culture of two homes selected from the sample based on theoretical considerations. The cases contrast with each other despite sharing some organizational characteristics such as size, ownership, and location: Both nursing homes, referred to as Home A and Home B, are rather small (30 beds), ecclesiastically managed, and located in a rural area with similar infrastructural challenges. Nevertheless, there are obvious interhome contrasts regarding living, thinking, and (inter-)acting. Thus, the cases depict how cultures permeate nursinghome life and practices. Further, they exemplify the identified characteristics of the dimensions and the application of the analytical tool: The overall cultures of Home A and Home B, reconstructed from the interviews, are grasped systematically by looking at the positions of the homes along the 15 dimensions of the introduced analytical tool. While marking aspects specific to staff, residents, or managers explicitly, it is a future task to explore who shapes which elements of the overall culture under which conditions. 
In Home A, both staff and residents view young and old people as categorically distinct. This is expressed, among others, in their statements about the pleasures of young people which should not be disturbed by the sight of agerelated decay, or about the lack of offers for older adults outside the care homes: The town is said to be "tailored toward young people." Interviewees in this home believe in the invariance and naturalness of aging. Especially residents display perceptions of aging perceived as an anthropological process of loss (i.e., leading to increasing dysfunctionality) and homogenization, which is thought to blur differences or even social inequalities. While it appears positive when people can say "When it comes to aging neither money nor class matter," at least some of the residents interviewed regret being deprived of chances to reproduce otherwise relevant roles, for example, those associated with gender. Nevertheless, all acknowledge that older people, and nursing-home residents in particular, are freed from norms, expectations, and pressures to be productive and active. However, several comparisons of people's physical and mental states are made to the disadvantage of older people. For example, residents say: "I am no longer able to ...," while the staff associates being old with being outdated or lagging behind time, being in need of help, and disinterested in - or even afraid of - (external) social life. This seems to result in the disappearance of older people from public life. (Attributing this observation to conceptualizations of age(ing) rather than to the location of the nursing home far from the center of town is supported by the fact that this organizational characteristic is shared with Home B.) Life within the home is further marked by primarily impersonal relationships and professional-emotional distanced interactions: Despite the physical closeness, in-home contacts remain superficial, while the contractually arranged social roles legitimize demanding and receiving help. Thus, residents, employees, and managers talk about standardized care procedures based upon formally defined roles and responsibilities that rest on functional differentiation. This is said to come with professionalization, predictability, and reliability. While the associated efficiency is valued by the staff, residents discuss the focus on standards ambivalently: They recognize it as contributing to care quality, albeit only regarding vital necessities. Anything beyond that is said to be a private matter, available if one has access to the relevant resources such as money, a social network, and familial presence. Then, care is portrayed as potentially individual and encompassing a wide range of alternatives to standard care and supplements to the coverage of basic needs. This points toward persistent and emerging social differences and inequalities that exist despite the presumed equalizing effect of aging.
In contrast, in Home B there seem to be no categorical separations of young/old people. Instead, just like the staff, the residents display differences as gradual and as an effect of individual biological condition or personality. Combined with the perception of aging as an irreversible, unavoidable, but modifiable change encompassing decay as well as gains and personal growth until the end this results in (a) the appreciation of aging as a heterogeneous process, impacted by social and environmental aspects as well as personal efforts, and (b) a capacity-tailored, interest-based, and individuality-respecting treatment. The employees interviewed, including the manager of Home B, stress a primary orientation toward the well-being, life, and care quality of residents, which are reported to profit from the appreciation of heterogeneity through the continued relevance of personal traits. Simultaneously, however, the awareness of the modifiability of aging raises questions about individual responsibilities concerning reasonable lifestyles, especially regarding health. Thus, how much care is required and whether people are entitled to receive it depends on their past actions; support is conditional. There seems to be some idea of mutual exchange. Accordingly, older people are required to actively contribute to the community until the very end. This seems to relate to the presence of older people in outside life as well as occupational offers. Interviewees speak of having the "free choice" regarding the content of their occupations but also indicate the presence of pressure to choose one. Thus, not even residents are entitled to relax, as that would mean being ungrateful for remaining capacities: "Good residents" must display activity. Further, psychological needs are supposed to be satisfied through productivity, such as being a "reading granny." Consequently, interviews with residents and employees responsible for physical care point toward normatively demanded "right" ways of being old and notions of having to earn the respect shown to them. Nevertheless, there seems to be a certain intergenerational solidarity stretching beyond the nursing home - and beyond familial and personal relationships. However, the demand for solidarity is neither connected solely to opportunity structures nor depicted as unconditional or as all-encompassing, even if certain forms of responsibility for relatives can be enforced through control exercised by entities external to the home, such as the state.

\section{Discussion}

In the above, I showed that culture matters and that cultures permeate the whole life within nursing homes. I developed an analytical tool and introduced it to describe practical similarities and differences that exist despite similarities 


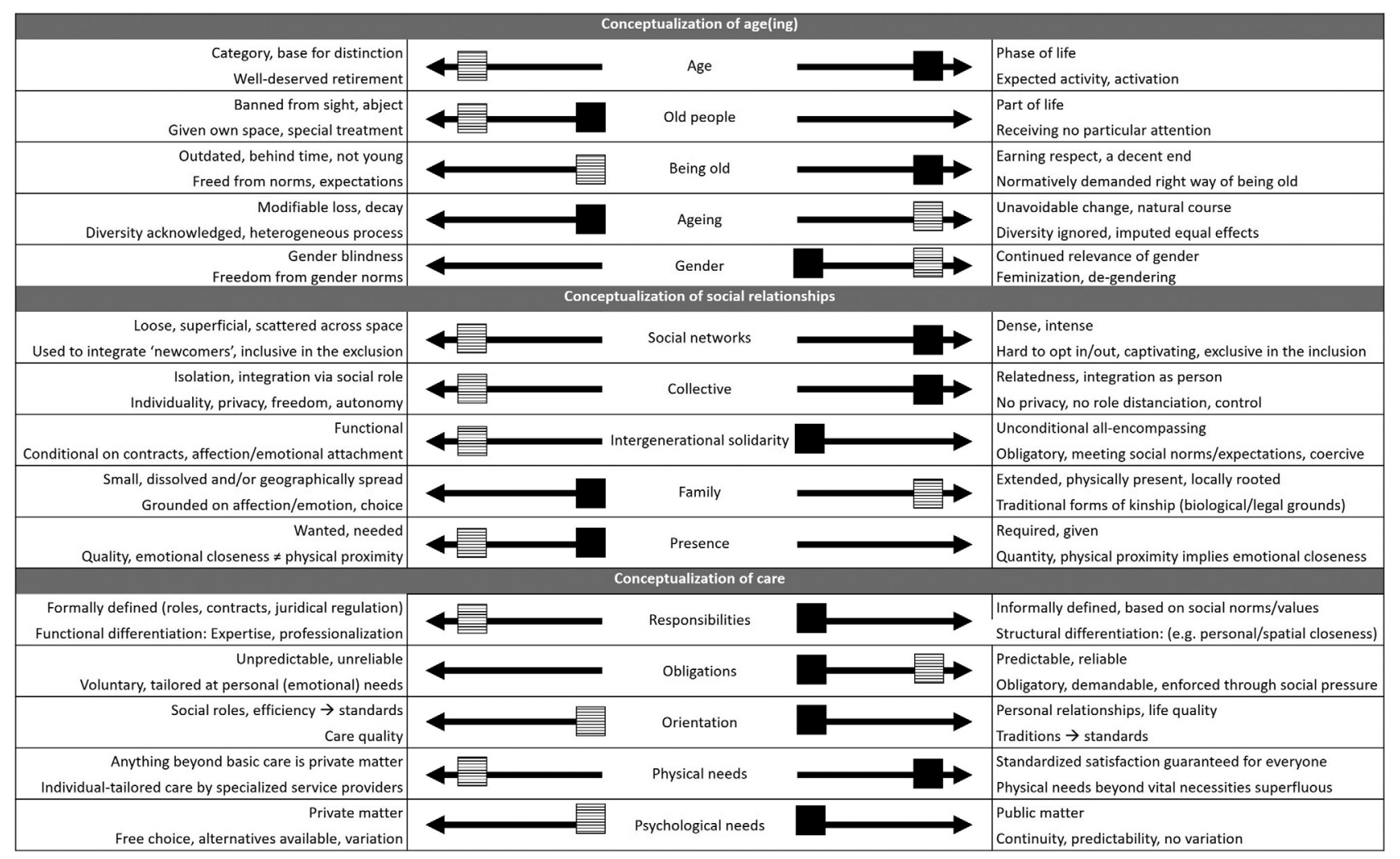

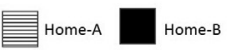

Figure 2. Visualization of case studies' overall culture.

related to organizational parameters such as location, size, and management. The application of this tool was exemplified regarding two empirical cases revealing that conceptualizations of age(ing), social relationships, and care impact the (expected) treatment of older people, their understanding of roles, and how resources such as money and employees are deployed. Figure 2 adds to this by representing one possible illustration of the tool and how it can be used not only for describing, identifying, and comparing, but also for visualizing locally effective cultures. This reveals how cultures figure as dissimilar patterns of positions along the dimensions that are presumed to appear and vary systematically. Thus, it becomes obvious, for instance, how much and in which ways Home A and Home B differ.

\section{Ambivalances}

While culture interlinks with all practices and facets of life in homes, different cultures or cultural aspects may be effective at different levels, such as the home, staff, and residents. Their co-occurrence can result in ambivalences, which are traced back to structural foundations that can be grasped in the terms of the analytical tool. Thus, they need to be qualified neither normatively nor in reference to an ideal or standard. Below I exemplify this regarding ambivalences that reappeared within the interviewees and the scientific literature cited.

First, ambivalences can result from contradictory features existing within a dimension or the co-occurrence of positively and negatively interpreted features given within one position (cf. the example description of the poles of the dimensions in Figure 2). For instance, Home $\mathrm{A}$ and Home B demonstrate that nursing home's relation to the local community as well as the inclusion of the residents in social networks is viewed as entailing simultaneously benefits (e.g., support) and disadvantages (e.g., control), or that the accommodation of older people in care facilities may correspond to high-end care and social disintegration, to anonymity/isolation and autonomy/privacy.

Second, ambivalences can result from contradictions between positions taken regarding different dimensions, because this entails opposing interpretations of circumstances or suggests contradictory actions. For instance, positions taken regarding the dimensions of age, aging, being old, and old people shape the perception of the disappearance of older people from public life and the interpretation of age-segregated spaces as measures of exclusion or of protection by meeting or counterbalancing a decrease in 
abilities. Home A and Home B revealed further how positions taken along dimensions can clash or generate extremely different results: Perceiving aging as a heterogeneous temporal process, for instance, may be accompanied by an imputation of self-responsibility for care and conditional solidarity or the acceptance/rejection of certain physical and psychological needs.

Third, ambivalences may occur if overall conceptualizations or whole cultures contradict each other. The former was the case in Home B, where the overall conceptualization of social relationships and the overall conceptualization of care entail consequences for late-life which tend to collide with each other and for some interviewees, especially residents, cause tensions, disappointment or feelings of guilt, and ambivalences. Further, the contradiction of whole cultures is depicted by the comparison of Home A and Home B. Figure 2 visualizes two different cultures locally effective. It seems likely that conflicts and ambivalences may be experienced, for example, in the case of relocation or migration: Someone socialized in the culture of Home A can feel displaced in Home B or vice versa.

Consequently, the analytical tool can be applied for (a) describing cultures of late-life in nursing homes; (b) explaining differences between homes for older people which resemble each other in terms of organizational parameters as well as practical similarities on-site despite organizational distinctiveness; (c) identifying the extent of cultural differences/similarities; (d) describing, maybe even predicting, the occurrence of ambivalences without presupposing their existence or quality; and (e) appreciating and dealing with complexity: Neither the evaluation of viewpoints concerning discussed themes or conceptualizations of age(ing), social relationships, and care nor of ambivalences is straightforward because the whole picture needs to be looked at.

Thus, the value of the presented findings lies in acknowledging a broad set of factors relevant to age(ing) in nursing homes, and in pointing toward a concept (locally effective culture) for its theorization as well as in providing a tool for analysis at various levels (e.g., residents/caring staff, organization), or across different homes. Hence, these are the benefits of the analytical tool:

- Applicability for discovering patterns of positions across dimensions, and for visualizing and distinguishing cultures systematically without curtailing the analysis or interpretation by presupposing the existence of cultures or similarities/differences;

- Usability for theorists and practitioners alike for describing and explaining possible effects of and contradictions between different positions (such as those taken by different generations, stakeholders, or actors) scientifically reconstructable or practically observable by paying attention to the accounts of (older) people, employees, etc., as well as for dealing with ambivalences: The identification of ambivalences' structural foundation can help to define advisable and practical reactions or even solutions for tackling them.

\section{Reflection and Outlook}

Despite these benefits and gains related to the insights gained through this project, there is still a long way to go. First, empirical limitations have to be overcome. This study was exploratory, and the data considered were selective. For instance, only Bavarian nursing homes were visited, and participation was voluntary. Thus, the empirical material may be positively biased: Maybe only those homes participated in which the management had an interest in residents' quality of life or believed that it had nothing to hide. Further, homes might have preselected residents who conform to the locally practiced culture, which could have caused an overestimation of compatibility and satisfaction as well as an underestimation of contradictions, mismatches, and ambivalences.

Additionally, the theoretical shortcomings of this study should be addressed. Normative and evaluative premises penetrate the entire research landscape on age(ing) and care as well as the practice of dealing with age(ing) and caring for older people - and, therefore, also the presented analytical tool informed by it. Consequently, the premises should be named and reflected upon, preferably along the facets of culture mentioned in this paper's Introduction. Moreover, the analytical tool should be grounded ethically. Possible references for this are Sen's $(2000,2011)$ and Nussbaum's $(2000,2007)$ capability approach, Kruse's (2017) emphasis on potentials and vulnerabilities, or discussions about human rights (General Assembly, 2013).

Therefore, future research is invited to amend the findings of this study and to refine the analytical tool by the following:

- Broadening the empirical base and testing the transferability of the findings of this study and the applicability of the analytical tool to other constellations of age(ing) such as noninstitutional, private care.

- Expanding considered dimensions, for example, by including individual characteristics, religion, class, ethnicity.

- Differentiating in-home cultures in more detail, for example, by distinguishing the influence of managers, staff, and residents upon the overall locally effective cultures.

- Exploring how cultures relate to costs or how locally effective cultures (re)produce or mitigate social differences, and how this is impacted by wider contextual factors such as systems of financing age(ing) or welfare types. 
However, researchers and practitioners should already now feel encouraged to use the tool presented to identify and compare locally effective cultures and to identify specific causes and effects of ambivalence as exemplified above. Thus, findings depicted above as well as insights that will possibly be reached against the backdrop of this paper might inform policymaking. It would be a small improvement alone be if a broader set of factors were considered when it comes to aging and old-age care, that is, if the mentioned conceptualizations of age(ing), social relationships, and care were taken into account rather than focusing (solely) on "the organization" and related quantifiable criteria. It seems useful, if not even ethically required, to broaden the perception of old-age care and to pay attention to culture in a nuanced way, reflecting those locally effective, relevant on different levels, or for different stakeholders. Thus, all involved actors, especially the older or vulnerable ones, should be given a voice (Döbler, 2019b). This could facilitate mutual understanding (Döbler, 2019b; Lehmann \& Brinkmann, 2019), prevent the occurrence, or ease the effects of ambivalences. Furthermore, doing all this - not only theoretically but also practically might improve the experienced quality of life for older people and contribute to the realization of more respect and dignity in care contexts (Klotz et al., 2017).

\section{Conclusion}

Against the backdrop of (a) empirical material gathered in a qualitative project conducted in Bavarian nursing homes and (b) a qualitative literature overview about age(ing) and care, I showed that age (ing) in nursing homes and quality of life are not (solely) matters of the organizational characteristics of a nursing home but matters of culture and cultural alignment (too). I developed and introduced an analytical tool composed of 15 thematic dimensions that are continua with contrasting attitudes toward a theme conceptualized as poles. I showed, by way of example, that one can find any position between extremes and any combination of positions across dimensions, even if it seems likely that patterns of positions reoccur. Cultures are supposed to figure as dissimilar patterns of positions along the dimensions assumed to vary systematically, so that one can find not only locally effective cultures but also similar cultures across different homes. Thus, the analytical tool is supposed to help to order empirical reality as well as to understand and to explain the manifestation, cause, and nature of ambivalences (Bengtson et al., 2002; Connidis \& McMullin, 2002; Lüscher \& Hoff, 2013). While this analytical tool needs to be refined and adapted, its current version can already inform both theory and praxis: It aids in theoretically acknowledging practically relevant complexities, in grasping and analyzing systematically empirical conditions; it helps practitioners to change or tackle sources and/or related consequences; and it facilitates choosing the "right" age-care-setting for oneself or relatives by avoiding cultural mismatches.

\section{References}

Allen, P., \& Cherry, K. (2006). Race relations in the nursing home setting. Race. Gender \& Class, 13(1/2), 36-45.

Artner, L. (2018). Materialities in and of institutional care for elderly people. Frontiers in Sociology, 3, Article 1. https://doi. org/10.3389/fsoc.2018.00030

Ayalon, L. \& Tesch-Roemer, C. (Eds.). (2018). Contemporary perspectives on ageism. Springer.

Barnes, S. (2006). Space, choice and control, and quality of life in care settings for older people. Environment and Behavior, 38(5), 589-604. https://doi.org/10.1177/0013916505281578

Bengtson, V., Giarrusso, R., Mabry, J. B., \& Silverstein, M. (2002). Solidarity, conflict, and ambivalence: Complementary or competing perspectives on intergenerational relationships? Journal of Marriage and Family, 64(3), 568-576. https://doi.org/ 10.1111/j.1741-3737.2002.00568.x

Bengtson, V. \& Lowenstein, A. (Eds.). (2003). Global aging and challenges to families. De Gruyter.

Biggs, S. (2004). Age, gender, narratives, and masquerades. Journal of Aging Studies, 18(1), 45-58. https://doi.org/ 10.1016/j.jaging.2003.09.005

Börsch-Supan, A., Brandt, M., Litwin, H., \& Weber, G. (Eds.) (2013). Active ageing and solidarity between generations in Europe. De Gruyter.

Braun, V., \& Clarke, V. (2006). Using thematic analysis in psychology. Qualitative Research in Psychology, 3(2), 77-101. http://eprints.uwe.ac.uk/11735

Cardona, B. (2008). "Healthy Ageing" policies and anti-ageing ideologies and practices. Medicine, Health Care, and Philosophy, 11(4), 475-483. https://doi.org/10.1007/s11019-008-9129-z

Clark, P., \& Bowling, A. (1990). Quality of everyday life in long stay institutions for the elderly. Social Sciences Medicine, 30(11), $1201-1210$.

Connidis, I. A., \& McMullin, J. A. (2002). Ambivalence, family ties, and doing sociology. Journal of Marriage and Family, 64(3), 594-601.

Cook, G., Thompson, J., \& Reed, J. (2015). Re-conceptualising the status of residents in a care home. Ageing and Society, 35(8), 1587-1613. https://doi.org/10.1017/S0144686X14000397

Craveiro, D., Matos, A., Silva, S., Martinez-Pecino, R., \& Schouten, M. (2013). Intergenerational support: The role of gender and social networks. In A. Börsch-Supan, M. Brandt, H. Litwin, \& G. Weber (Eds.), Active ageing and solidarity between generations in Europe (pp. 359-368). De Gruyter.

Crossley, N., Bellotti, E., Edwards, G., Everett, M., Koskinen, J., \& Tranmer, M. (2015). Social network analysis. Sage.

Daatland, S. O. (2016). Quality of life and ageing. In V. Bengtson (Ed.), The Cambridge handbook of age and ageing (pp. 371-377). Cambridge University Press.

Degnen, C. (2007). Minding the gap: The construction of old age and oldness amongst peers. Journal of Aging Studies, 21(1), 69-80. https://doi.org/10.1016/j.jaging.2006.02.001

Dittmann-Kohli, F. (2016). Self and identity. In V. Bengtson (Ed.), The Cambridge handbook of age and ageing (pp. 275-291). Cambridge University Press. 
Döbler, M.-K. (2019a). Co-presence and family. In M. HalatchevaTrapp, G. Montanari, \& T. Schlinzig (Eds.), Family and space (pp. 11-22). Routledge.

Döbler, M.-K. (2019b). Mehr als nur Pflege [More than just care]. APuZ, 69(33-34), 18-23. http://www.bpb.de/apuz/294920/ mehr-als-nur-pflege-care-in-altenpflegeheimen

Döbler, M.-K. (2020a). Menschenrechte und Lebensqualität in Alten (pflege)heimen [Human rights and the quality of life in homes for old people]. In A. Frewer, S. Klotz, C. Herrler, \& H. Bielefeldt (Eds.), Gute Behandlung im Alter? (pp. 175-222). TranscriptVerlag. https://doi.org/10.14361/9783839451236-009

Döbler, M.-K. (2020b). Nicht-Präsenz in Paarbeziehungen: Lieben und Leben auf Distanz [Non-presence in romantic relationships: Loving and living from a distance]. VS Verlag für Sozialwissenschaften.

Einiö, E., Guilbault, C., Martikainen, P., \& Poulain, M. (2012). Gender differences in care home use among older Finns and Belgians. Population, 67(1), 71-95.

Esping-Andersen, G. (1999). The household economy. In G. Esping-Andersen (Ed.), Social foundations of postindustrial economies (pp. 47-72). Oxford University Press.

Farquhar, M. (1995). Elderly people's definition of quality of life. Social Sciences Medicine, 41(10), 1439-1446.

Federal Statistical Office. (2016). Older people in Germany and the EU. https://www.destatis.de/publications

Foster, L., \& Walker, A. (2015). Active and successful aging: A European policy perspective. Gerontologist, 55(1), 83-90. https://doi.org/10.1093/geront/gnu028

General Assembly. (2013). Toward a comprehensive and integral international legal instrument to promote and protect the rights and dignity of older persons: RES/67/139. United Nations. https://undocs.org/A/RES/67/139

Giddens, A. (2003). Modernity and self-identity: Self and society in the late modern age. Polity Press.

Gilleard, C. (2016). Cultural approaches to the ageing body. In V. Bengtson (Ed.), The Cambridge handbook of age and ageing (pp. 156-164). Cambridge University Press.

Goffman, E. (1961). Asylums. Anchor Books.

Gubrium, J. (2016). The social worlds of old age. In V. Bengtson (Ed.), The Cambridge handbook of age and ageing (pp. 310-315). Cambridge University Press.

Hall, J., \& Neitz, M. J. (1993). Culture: Sociological perspectives. Prentice Hall.

Hall, S., Longhurst, S., \& Higginson, I. J. (2009). Challenges to conducting research with older people living in nursing homes. BMC Geriatrics, 9, Article 38. https://doi.org/10.1186/14712318-9-38

Harris, R., \& Dyson, E. (2001). Recruitment of frail older people to research. Journal of Advanced Nursing, 36(5), 643-651. https:// doi.org/10.1046/j.1365-2648.2001.02029.x

Heinzelmann, M. (2004). Das Altenheim - immer noch eine ,, Totale Institution"? [Old people's home: still a "total institution"?]. Cuvillier.

Hills, M. D. (2002). Kluckhohn and Strodtbeck's values orientation theory. Online Readings in Psychology and Culture, 4(4). https:// doi.org/10.9707/2307-0919.1040

Hubbard, G., Downs, M. G., \& Tester, S. (2003). Including older people with dementia in research. Aging \& Mental Health, 7(5), 351-362. https://doi.org/10.1080/1360786031000150685

Jecker, N. S. (2017). How to think about age-group justice: The capabilities approach. In M. Schweda, L. Pfaller, K. Brauer, F. Adloff, \& S. Schicktanz (Eds.), Planning later life (pp. 131-146). Routledge.

Jenks, C. (1993). Culture: Key ideas. Routledge.

Kane, R. A. (2001). Long-term care and a good quality of life: Bringing them closer together. The Gerontologist, 41(3), 293-304.
Kelle, U., Metje, B., \& Niggemann, C. (2014). Datenerhebung in totalen Institutionen als Forschungsgegenstand einer kritischen gerontologischen Sozialforschung [Data collection in total institutions as a research object of critical gerontological social research]. In A. Amann \& F. Kolland (Eds.), Alter(n) und Gesellschaft (2nd ed., pp. 175-206). Springer VS.

Klotz, S., Bielefeldt, H., Schmidhuber, M., \& Frewer, A. (Eds.). (2017). Healthcare as a human rights issue. Transcript Verlag.

Kristeva, J. (1982). Powers of horror: An essay on abjection. Columbia University Press.

Kruse, A. (2017). Old age, potentials, and vulnerability. In M. Schweda, L. Pfaller, K. Brauer, F. Adloff, \& S. Schicktanz (Eds.), Planning later life (pp. 75-88). Routledge.

Lang, G., Löger, B., \& Amann, A. (2007). Well-being in the nursing home: A methodological approach toward the quality of life. Journal of Public Health, 15(2), 109-120. https://doi.org/ 10.1007/s10389-006-0082-0

Lehmann, O., \& Brinkmann, S. (2019). "I'm the one who has written this": Reciprocity in writing courses for older adults in Norway. International Journal of Qualitative Studies on Health and WellBeing, 14(1), Article 1650586. https://doi.org/10.1080/ 17482631.2019 .1650586

Leopold, T., \& Raab, M. (2011). Short-term reciprocity in late parent-child relationships. Journal of Marriage and Family, 73(1), 105-119.

Lüscher, K. (2002). Intergenerational Ambivalence: Further steps in theory and research. Journal of Marriage and Family, 64(3), 585-593.

Lüscher, K., \& Hoff, A. (2013). Intergenerational ambivalence: Beyond solidarity and conflict. In I. Albert \& D. Ferring (Eds.), Intergenerational relations (pp. 39-64). Policy Press. https:// doi.org/10.1332/policypress/9781447300984.003.0004

Maas, M. L., Kelley, L. S., Park, M., \& Specht, J. P. (2002). Issues in conducting research in nursing homes. Western Journal of Nursing Research, 24(4), 373-389. https://doi.org/10.1177/ 01945902024004006

Mattiasson, A.-C., \& Andersson, L. (1997). Quality of nursing home care assessed by competent nursing home patients. Journal of Advanced Nursing, 26(6), 1117-1124. https://doi.org/10.1046/ j.1365-2648.1997.00464.x

McDaniel, C., \& Stumpf, L. (1993). The organizational culture: Implications for nursing service. Journal of Nursing Administration, 23(4), 54-60.

Michel, S., \& Peng, I. (2017). Introduction. In S. Michel \& I. Peng (Eds.), Gender, migration, and the work of care: A multi-scalar approach to the Pacific Rim (pp. 3-22). Palgrave Macmillan.

Nussbaum, M. C. (2000). Women and human development: The capabilities approach. Cambridge University Press.

Nussbaum, M. C. (2007). Frontiers of justice. The Belknap Press of Harvard University Press.

Park, J., Fung, H. H., Rothermund, K., \& Hess, H. M. (2019). The impact of perceived control and future-self views on preparing for the old age. The Journals of Gerontology. Advance online publication. https://doi.org/10.1093/geronb/gbz138

Peng, I. (2018). Culture, institution and diverse approaches to care and care work in East Asia. Current Sociology, 66(4), 643-659. https://doi.org/10.1177/0011392118765211

Pesonen, H.-M., Remes, A. M., \& Isola, A. (2011). Ethical aspects of researching subjective experiences in early-stage dementia. Nursing Ethics, 18(5), 651-661. https://doi.org/10.1177/ 0969733011408046

Pfaller, L., \& Schweda, M. (2019). Excluded from the good life? Social Inclusion, 7(3), 44-53. https://doi.org/10.17645/si.v7i3.1918

Pickard, S. (2019). Age war as the new class war? Contemporary representations of intergenerational inequity. Journal 
of Social Policy, 48(2), 369-386. https://doi.org/10.1017/ S0047279418000521

Powers, B. A. (1992). The roles staff play in the social networks of elderly institutionalized people. Social Science \& Medicine, 34(12), 1335-1343. https://doi.org/10.1016/0277-9536(92)90142-D

Romaioli, D., \& Contarello, A. (2019). "I'm too Old for ...": Looking into a self-sabotage rhetoric and its counter-narratives in an Italian setting. Journal of Aging Studies, 48, 25-32. https://doi. org/10.1016/j.jaging.2018.12.001

Rupprecht, F. S., Dutt, A. J., Wahl, H.-W., \& Diehl, M. K. (2019). The role of personality in becoming aware of age-related changes. GeroPsych, 32(2), 57-67. https://doi.org/10.1024/1662-9647/ a000204

Schultz Lee, K. (2010). Gender, care work, and the complexity of family membership in Japan. Gender \& Society, 24(5), 647-671. https://doi.org/10.1177/0891243210382903

Schweda, M., Wöhlke, S., \& Inthorn, J. (2015). "Not the years in themselves count": The role of age for European citizens' moral attitudes toward resource allocation in modern biomedicine. Journal of Public Health, 23(3), 117-126. https://doi.org/ 10.1007/s10389-015-0664-9

Scott-Findlay, S., \& Estabrooks, C. A. (2006). Mapping the organizational culture research in nursing: A literature review. Journal of Advanced Nursing, 56(5), 498-513. https://doi.org/ 10.1111/j.1365-2648.2006.04044.x

Sen, A. (2000). Development as freedom. Anchor Books.

Sen, A. (2011). The idea of justice. Belknap Press of Harvard University Press.

Shadish, W. R., \& Bootzin, R. R. (1984). Nursing homes: The new total institution in mental-health policy. International Journal of Partial Hospitalization, 2(4), 251-262.

Sherratt, C., Soteriou, T., \& Evans, S. (2007). Ethical issues in social research involving people with dementia. Dementia, 6(4), 463-479. https://doi.org/10.1177/1471301207084365

Silverstein, M., Gans, D., Lowenstein, A., Giarrusso, R., \& Bengtson, V. (2010). Older parent-child relationships in six developed nations. Journal of Marriage and Family, 72(4), $1006-1021$.

Staehlin, H. (2016). Promoting health and wellbeing in later life. In V. Bengtson (Ed.), The Cambridge handbook of age and ageing (pp. 165-177). Cambridge University Press.

Tam, M. (2014). Understanding and theorizing the role of culture in the conceptualizations of successful aging and lifelong learning. Educational Gerontology, 40(12), 881-893. https://doi.org/ 10.1080/03601277.2014.907072

Tronto, J. (2013). Caring democracy: Markets, equality, and justice. New York University Press.

Van Dyk, S. (2014). The appraisal of difference. Journal of Aging Studies, 31, 93-103. https://doi.org/10.1016/j.jaging.2014.08.008

Van Dyk, S. (2016). The othering of old age. Journal of Aging Studies, 39, 109-120. https://doi.org/10.1016/j.jaging.2016.06.005

Veer, A. J. E., \& Kerska, A. (2001). Feeling at home in nursing homes. Journal of Advanced Nursing, 35(3), 427-434.

Vries, B. de. (2018). The unsung bonds of friendship and caring among older adults. Journal of the American Society on Aging, 42(3), 77-81.
Westin, L., \& Danielson, E. (2007). Encounters in Swedish nursing homes. Journal of Advanced Nursing, 60(2), 172-180. https:// doi.org/10.1111/j.1365-2648.2007.04396.x

Zhang, W., \& Wang, Y. (2010). Meal and residence rotation of elderly parents in contemporary rural northern China. Journal of Cross-Cultural Gerontology, 25(3), 217-237. https://doi.org/ 10.1007/s10823-010-9121-y

Zweig, S. C., \& Oliver, D. P. (2009). Returning from the total institution to a home environment. Journal of Housing for the Elderly, 23(1-2), 116-129. https://doi.org/10.1080/02763890802665064

\section{History}

Received August 29, 2021

Accepted October 22, 2021

Published online December 1, 2021

\section{Acknowledgments}

This research draws on an analysis done within the project "Quality of Life of Residents of Old People's (Nursing) Homes in Bavaria," funded by the Bayerisches Staatsministerium für Bildung und Kultus, Wissenschaft und Kunst. I want to thank the anonymous reviewers whose comments and suggestions contributed significantly to the quality of this paper.

\section{Conflict of Interest}

This research is based on material gathered within the project "Life Quality (LQ) of Residents of Old People's (Nursing) Homes (HOME) in Bavaria," which is part of the research network ForGenderCare (www.forgendercare.de), funded by the Bayrisches Staatsministerium für Bildung und Kultus, Wissenschaft und Kunst. The sponsor had no influence on the collection or analysis of the data. The paper was written solely on my account; no one else was involved.

\section{Editorial Note}

The acting editor was Isabelle Albert.

\section{Funding}

Open access publication enabled by Friedrich-Alexander University Erlangen-Nuremberg.

\section{ORCID}

Marie-Kristin Doebler

(iD https://orcid.org//0000-0002-9190-6734

\section{Dr. phil. Marie-Kristin Doebler}

Institute of Sociology

Friedrich-Alexander University Erlangen-Nuremberg

Kochstraße 4

91054 Erlangen

Germany

marie-kristin.doebler@fau.de 